\title{
War! What is it good for? Mustard gas medicine
}

Cite as: CMAJ 2017 February 27;189:E321-2. doi: 10.1503/cmaj.161032

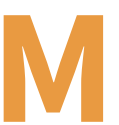

ustard gas, which was named for its yellow-brown colour and mustard smell, has been in the news lately because of its use in the Middle East, including against civilians in Syria and Iraq. Many North Americans would be shocked, however, to learn of the deep connection between mustard gas, a chemical weapon, and medical research.

Mustard agents have a long history in American medical research, beginning with the work of Dr. Edward and Helen Krumbhaar during World War I. ${ }^{1}$ By World War II, at least two dozen medical researchers transformed mustard agents into cancer chemotherapy. In the 1940s, sulfur mustard, commonly called mustard gas, and nitrogen mustard, a derivative of mustard gas, became a new form of cancer treatment. ${ }^{2}$ The search for medical applications of mustard compounds continued into the 1970s. For example, in 1972, Dr. Rudolf L. Baer, a renowned dermatologist, published the results of a study in which he used nitrogen mustard to treat psoriasis in nine patients. ${ }^{3}$

Baer, who was on the faculty at New York University School of Medicine for more than 50 years, was part of the World War II generation of physician-researchers who spent a great deal of time studying the effects of mustard agents. In the 1940s, he and hundreds of physicians and scientists from a number of fields, including biochemistry, pathology, pharmacology, physiology, hematology and dermatology, conducted military medical research on dozens of chemical warfare agents, particularly mustard gas. ${ }^{2-4}$ Medical scientists in Canada, the United States, the United Kingdom and Australia conducted toxicity studies as part of Allied preparation for chemical warfare. After the terrifying experiences of gas warfare during World War I, the Allied nations wanted to be ready to deploy gas weapons and defend against them if necessary. ${ }^{5,6}$

During World War II, medical scientists developed cancer chemotherapy from mustard agents because these were the poisons they knew best. Dr. Cornelius Rhoads, for example, was the head of the Medical Division of the US Chemical Warfare Service and also director of the SloanKettering Institute for Cancer Research of Memorial Hospital in New York City. Cancer researchers built on their own research experience into chemical warfare. Wartime scientific research involved both medical research for military purposes through mustard gas experiments involving soldiers, many of whom were enticed or ordered to volunteer, and medical applications of military research through mustard

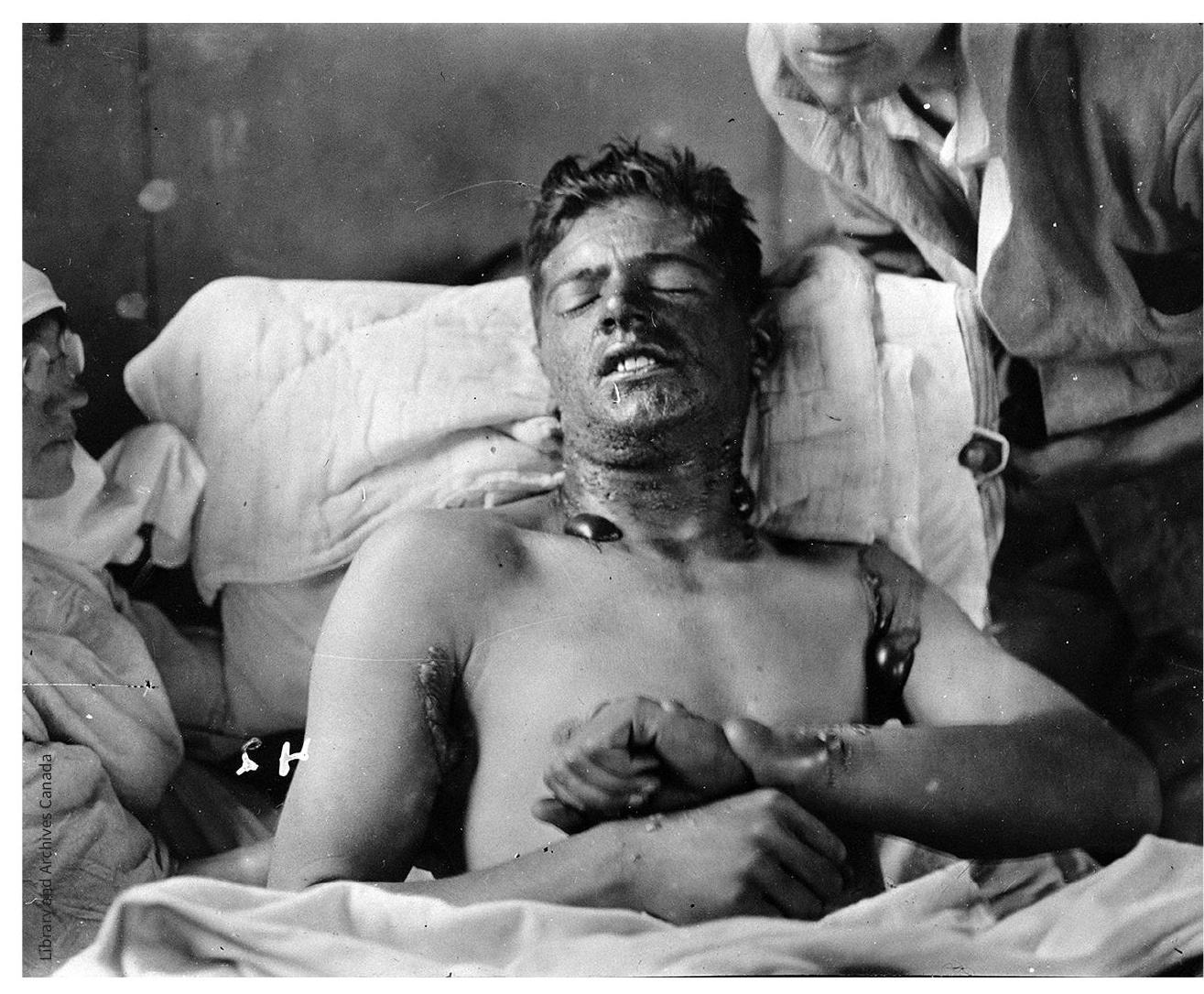

Canadian soldier in France during World War I. agent experiments involving patients with cancer, who hoped for relief and maybe even a cure. Military and civilian scientific research were deeply intertwined. ${ }^{5,7}$

In the early 1940s, doctors associated with Yale University, the University of Chicago and Memorial Hospital conducted the first therapeutic experiments with the intravenous use of mustard agents by administering sulfur mustard and nitrogen mustard into the veins of cancer patients. Although some patients did benefit temporarily, especially those with Hodgkin disease and lymphosarcoma, problems with chemoresistance and chemotoxicity mustard agents are still used today to treat cancer, including one known as Mustargen (mechlorethamine). emerged. ${ }^{2,8}$ Several drugs derived from

Canadian soldier in France during World Warl. 
The connection between chemical weapons and cancer treatment may seem surprising, even disturbing, to us. However, for the physician-researchers and medical scientists at the time, it was the logical outcome of their wartime research on mustard gas. They learned about the medical effects from toxic exposures of servicemen, both the unintentional from a wartime disaster in Bari, Italy, and the intentional in the mustard gas experiments conducted at military and civilian facilities, including medical schools. Their interdisciplinary research produced an enormous amount of data on the health effects of mustard agents on animals and humans. However, the military heritage of cancer chemotherapy is not common knowledge because of longstanding government secrecy regarding chemical weapons research. ${ }^{5}$

To be clear, it was not war itself that advanced medicine. ${ }^{9}$ The development of a new form of cancer control in the 1940s was due to the determination of physicians and scientists who deliberately tried to extract health care dividends from weapons of war. The mobilization for war provided the context for the kind of political will, government resources and human suffering that scientists drew on to expand medical knowledge. Medical researchers tapped into the available government resources, and during World War II, a major area of targeted funding was for the investigation of chemical warfare agents, particularly mustard gas and the nitrogen mustards.., 10
The creation of cancer chemotherapy depended on the contributions of servicemen and people with cancer who participated in experiments with mustard agents. Soldiers, including those at Suffield Experimental Station in Alberta, took part in chemical warfare experiments as part of their wartime military service. They faced toxicity studies with mustard gas that included drop tests, field tests and even tests in gas chambers. ${ }^{6}$ In later years, many of these young, healthy enlisted men faced long-term health consequences from those toxic exposures. People with cancer took part in therapeutic experiments with mustard agents in hopes of finding some benefits, even if only for a short time. Together, researchers and research participants transformed mustard agents from chemical weapons into medical treatments. ${ }^{5}$

Medical oncology, which seeks to control cancer through chemotherapy, originated in the science of war and Allied preparation for gas warfare during World War II. It grew out of medical research for military benefits. Today, governments need to support medical research for its own sake and not to serve other agendas. As the history of chemotherapy reminds us, it was science, not war, that was good for medicine.

\section{Susan L. Smith PhD}

Department of History and Classics, Faculty of Arts, University of Alberta, Edmonton, Alta.

\section{References}

1. Krumbhaar EB, Krumbhaar HD. The blood and bone marrow in yellow cross gas (mustard gas) poisoning: changes produced in the bone marrow of fatal cases. J Med Res 1919;40: 497-508.

2. Moulton FR, editor. Approaches to tumor chemotherapy. Washington (DC): American Association for the Advancement of Science; 1947.

3. Baer RL, Michaelides P, Prestia AE. Failure to induce immune tolerance to nitrogen mustard. Intravenous administration preceding topical use in patients with psoriasis. J Invest Dermatol 1972;58:1-4.

4. Sulzberger MB, Baer RL, Kanof A, et al. Skin sensitization to vesicant agents of chemical warfare. J Invest Dermatol 1947;8:365-93.

5. Smith SL. Toxic exposures: mustard gas and the health consequences of World War II in the United States. New Brunswick (NJ): Rutgers University Press; 2017.

6. Avery D. The science of war: Canadian scientists and allied military technology during the Second World War. Toronto: University of Toronto Press; 1998.

7. Kutcher G. Contested medicine: cancer research and the military. Chicago: University of Chicago Press; 2009.

8. Karnofsky DA, Craver LF, Rhoads CP, et al. An evaluation of methyl-bis ( $\beta$-chloroethyl) amine hydrochloride and tris ( $\beta$-chloroethyl) amine hydrochloride (nitrogen mustards) in the treatment of lymphomas, leukemia, and allied diseases. In: Moulton FR, editor. Approaches to tumor chemotherapy. Washington (DC): American Association for the Advancement of Science; 1947:319-37.

9. Cooter R, Sturdy S. Of war, medicine and modernity: introduction. In: Cooter R, Harrison M, Sturdy $\mathrm{S}$, editors. War, medicine and modernity. Stroud (UK): Sutton Publishing; 1999:1-21.

10. Pickstone JV. Contested cumulations: configurations of cancer treatments through the twentieth century. Bull Hist Med 2007;81:164-96.

Funding: This project was funded by a grant from the Social Sciences and Humanities Research Council. The funding had no direct impact on the author's research or conclusions.

This article was solicited and has been peer reviewed. 